\title{
Effects of delay in anti-vascular endothelial growth factor intravitreal injections for neovascular age-related macular degeneration
}

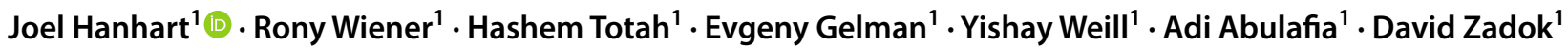

Received: 17 June 2021 / Revised: 24 October 2021 / Accepted: 18 November 2021 / Published online: 11 January 2022

(c) The Author(s), under exclusive licence to Springer-Verlag GmbH Germany, part of Springer Nature 2021

\begin{abstract}
Purpose To assess the impact of COVID-19-related delay in intravitreal injection timing on macular structure and visual acuity (VA) among patients treated for neovascular age-related macular degeneration (nvAMD).

Methods We reviewed demographic and clinical data and macular ocular computerized tomographic images of 34 patients (48 eyes, group A) who did not follow their injection schedule during the first wave of COVID-19 and compared them to 46 patients (71 eyes, group B) who did. Functional worsening was defined as a loss of at least 0.1 in decimal VA. Anatomic worsening was defined as new or increased subretinal/intraretinal fluids or new hemorrhage.

Results The planned mean \pm standard deviation intervals between the intravitreal injections were $5.7 \pm 2.7$ weeks for group A and $5.5 \pm 2.4$ weeks for group B $(P=0.60)$. The actual intervals were $13.6 \pm 6.8(7.9 \pm 5.2$ weeks' delay $)$ and $5.3 \pm 2.4$ weeks (no delay), respectively $(P<0.001)$. The best corrected visual acuity worsened in 23 group A eyes $(47.9 \%)$ and in 6 group B eyes $(8.5 \%)$ (odds ratio [OR] 9.97, $P<0.001$ ). Anatomic features indicative of nvAMD worsening were detected in 31 group A eyes (64.6\%) and in 16 group B eyes (22.5\%) (OR 5.73, $P<0.001)$. A new macular hemorrhage was observed in 4 group A eyes (8.3\%) and in no group B eyes $(P=0.09)$.

Conclusion Delay in timely retinal care during the COVID-19 restrictions period resulted in short-term negative outcomes, including macular bleeding, in nvAMD patients.
\end{abstract}

Keywords AMD $\cdot$ OCT $\cdot$ COVID-19 $\cdot$ Anti-VEGF $\cdot$ Delay $\cdot$ Disruption

\section{Key Messages}

- Anti-VEGF is the main treatment for neovascular AMD. Timely injections are necessary to maintain optimal vision. The COVID-19 pandemic disrupted retinal care.

- COVID-19 related delay in intravitreal injections has quantifiable repercussions on the retinal structure and function.

- Some of the caused damage may be irreversible.

Joel Hanhart

hanhart@szmc.org.il

1 Department of Ophthalmology, Shaare Zedek Medical Center, Affiliated to the Hebrew University, 12 Shmuel Bait St., 9103102 Jerusalem, Israel

\section{Introduction}

Anti-vascular endothelial growth factor (VEGF) intravitreal injections were quickly adopted in the mid-2000s as first-line treatment of neovascular age-related macular degeneration (nvAMD), revolutionizing the prognosis of this common 
condition with a grim natural history [1, 2]. The far-reaching anatomical and functional achievements of the treatment, however, come at the cost of a high level of the patient's compliance with regular ophthalmic exams, including retinal imaging by optical coherence tomography (OCT) and iterative injections. By 2019, millions of patients were regularly receiving intravitreal anti-VEGF injections [3]. According to published guidelines, treatment intervals of 3-4 months are best tolerated, but many patients require monthly treatments, with only a minority with preserved macular function able to be safely kept on observation alone [4]. At that time, it was observed that real-world data did not always reflect smooth results from registration studies. After several years of treatment, the mean visual acuity (VA) had nevertheless improved as compared with presentation, in spite of frequency of delivered injections being actually inferior to that reported in the literature $[5,6]$.

The COVID-19 pandemic severely disrupted retinal care. Patients were unable to arrive to medical centers or they were fearful of crowding at those institutions, and system resources were redirected to delivering emergent sight-saving therapy, thus deprioritizing routine eye care. For the first time since the introduction of intravitreal anti-VEGF therapy for nvAMD, long-standing treatment schedules of masses of patients were suddenly disrupted [7-22]. In Israel, a lockdown was announced from March to April 2020, in what was termed the "first wave of COVID-19." This abrupt change in treatment access enabled the examination of the ophthalmic sequelae of this pandemic-driven tactic. The objective of the present study was to examine the "first wave of COVID-19" behavioral, functional, and social changes on the macular structure and VA in patients who missed their scheduled intravitreal anti-VEGF injections during this time.

\section{Materials and methods}

\section{Participants and ethics}

This retrospective study included consecutive nvAMD patients who were scheduled for anti-VEGF injection by a single retina specialist $(\mathrm{JH})$ at the Shaare Zedek Medical Center, a tertiary ophthalmology center, from March to April 2020, the "first wave of COVID-19."

\section{Study design}

The nvAMD patients' data were retrieved from their electronic medical records, and included demographics, best corrected visual acuity (BCVA), complete ophthalmic biomicroscopic evaluation (including fundus examination by a retina specialist $[\mathrm{JH}]$ ), duration of treatment, the total number of anti-VEGF intravitreal injections since treatment initiation, dates and kinds of the anti-VEGF intravitreal injections before, during, and after the "first wave of COVID-19," as well as evaluation of macular SDOCT volumetric scans (Spectralis, Heidelberg Engineering, Germany) prior to and after this period. BCVA was measured by a registered ophthalmic nurse using a Snellen chart, and the measurements were decimalized in order to respectively define a gain or loss of $0.1 \mathrm{deg}^{-1}$ in VA as visual improvement or worsening.

The nvAMD patients were grouped according to their adherence to the planned treatment schedule during the first wave of COVID-19. Group A included patients who delayed injections by more than $50 \%$ of planned treatment. They consequently returned for consultation with a delay of over $7.9 \pm 5.2$ weeks past their scheduled treatment interval (equivalent to $150 \%$ of the planned interval). Group B included patients who followed their original treatment schedule throughout this period (less than 50\% delay).

Naïve patients, those not personally and exclusively followed by $\mathrm{JH}$, were excluded as well as those who did not return to clinic prior to June 172020.

All treated eyes had readable OCT images, and none sustained any significant non-AMD ocular events during the analyzed time period; therefore, none was excluded. All eyes underwent a dense volumetric macular scan (Heidelberg Spectralis, software version 6.9.4.0; Heidelberg Engineering GmbH, Germany; dense macular scan, high-speed mode, $>15$ images averaged, scan angle $20^{\circ}$, $5.9 \mathrm{~mm} \times 5.9 \mathrm{~mm}, \mathrm{X}$ scaling $11.47 \mu \mathrm{m} / \mathrm{pixel}$, and $\mathrm{Z}$ scaling $3.87 \mu \mathrm{m} /$ pixel).

Central macular thickness was measured as total retinal thickness in the central subfield of the Early Treatment of Diabetic Retinopathy Study (ETDRS) field by means of the embedded software (Heidelberg Spectralis, software version 2.51). Delineation accuracy was verified by a retina specialist. "Thickening" was defined as an increase $>50 \mu \mathrm{m}$ and "thinning" as a decrease $>50 \mu \mathrm{m}$. For further analysis, we also defined a central subfield change $<10 \%$ as "stability." At the beginning and end of the study period, the presence of subretinal and intraretinal fluids as well as the presence of blood was recorded for each eye at each clinical examination. All increases in the total amount of subretinal and intraretinal fluids were evaluated and recorded by the same retina specialist.

The primary outcome measure of the present study was the mean change in VA in nvAMD patients with a delay in their scheduled anti-VEGF treatment regimen during the first wave of COVID-19 to those with no delay. The secondary outcome measure was the difference in structural retinal changes between these 2 groups. The exclusion criterion was the occurrence of any non-AMD ocular event during the study period. 


\section{Statistical analyses}

Statistical analyses were performed with the Matlab R2020b (Mathworks Inc, Natick, MA) software package. Analyses were performed with the Kolmogorov-Smirnov test, Pearson $\chi^{2}$ analysis, Fisher exact test, and 2-sample $t$ test for unequal variances, depending upon the nature of the data and the hypothesis being tested. All tests were 2 -sided unless specified otherwise. An alpha value of 0.05 was used to determine statistical significance. While we present multiple functional and morphologic metrics of progress, these metrics are not independent of each other, and are presented to establish the multiple facets of deterioration with missed treatment. These data therefore do not meet the criteria for family wise error rate (FWER) correction, such as a Bonferroni test, of a large number of independent tests. Of note that though individual hypotheses were tested at significance level of alpha $=0.05$, all significant results save for change in SRF were significant at a level 0.001 or greater and would thus meet statistical significance even if a FWER correction was applicable.

\section{Results}

Group A included 48 eyes (34 patients), and group B included 71 eyes (46 patients). No eye was excluded due to a non-nvAMD event. Nineteen patients originally scheduled for injection for nvAMD during the first wave of COVID-19 did not return during the data collection period and were therefore excluded from the study.

The planned intervals between intravitreal injections were $5.7 \pm 2.7$ and $5.5 \pm 2.4$ weeks for groups $\mathrm{A}$ and $\mathrm{B}$, respectively $(P=0.60)$. The actual interval periods between intravitreal injections were $13.6 \pm 6.8$ and $5.3 \pm 2.4$ weeks, respectively $(P<0.001)$, representing a delay of $7.9 \pm 5.2$ weeks for group A.

\section{Patient characteristics from presentation to last pre-COVID-19 visit}

Table 1 summarizes the demographic and clinical characteristics of both study groups. In Israel, due to Health Medical Organizations' reimbursement policy, bevacizumab is given as first-line therapy in nvAMD. If clinical response is insufficient, patients are switched to ranibizumab or aflibercept. So, for a given patient, bevacizumab is first-line therapy, while other compounds can be delivered as second or third line. Some patients, not more responding to ranibizumab or aflibercept, are switched back to bevacizumab.

The patients in group A were significantly older than those in group B: $83.1 \pm 5.3$ vs. $78.0 \pm 7.4$ years, respectively $(P<0.001)$. Otherwise, the 2 groups were similar in sex (43\% males overall, $P=0.648)$, lens status $(58 \%$
Table 1 Baseline demographic and clinical characteristics of the 2 study groups

\begin{tabular}{llll}
\hline Variable & Group A & Group B & $P$ value \\
\hline $\begin{array}{l}\text { Patients, } n(\%) \\
\text { Sex }\end{array}$ & $34(42.5)$ & $46(57.5)$ & 0.553 \\
$\quad$ Male (\%) & $13(38)$ & $21(46)$ & 0.648 \\
$\quad$ Female (\%) & $21(62)$ & $25(54)$ & \\
Eyes, $n(\%)$ & $48(40)$ & $71(60)$ & \\
Age, $y$ mean \pm SD & $83.1 \pm 5.3$ & $78.0 \pm 7.4$ & $<\mathbf{0 . 0 0 1}$ \\
Lens status & & & \\
$\quad$ Phakic (\%) & $21(44)$ & $29(41)$ & 0.850 \\
$\quad$ Pseudophakic (\%) & $27(56)$ & $42(59)$ & \\
Compound & & & \\
$\quad$ Bevacizumab (\%) & $35(73)$ & $43(61)$ & 0.176 \\
$\quad$ Ranibizumab (\%) & $4(8)$ & $4(6)$ & 0.713 \\
$\quad$ Aflibercept (\%) & $9(19)$ & $23(33)$ & 0.140 \\
Treatment line & & & \\
$\quad$ First (\%) & $28(58)$ & $37(52)$ & 0.575 \\
$\quad$ Second (\%) & $5(10)$ & $16(23)$ & $\mathbf{0 . 0 1 3}$ \\
$\quad$ Third (\%) & $8(17)$ & $10(14)$ & 0.796 \\
$\quad$ Back (\%) & $7(15)$ & $8(11)$ & 0.588 \\
BCVA at presentation & $0.47 \pm 0.26$ & $0.43 \pm 0.34$ & 0.500 \\
(mean \pm SD) & & & \\
Treatment duration, $y$ & $2.69 \pm 2.09$ & $2.33 \pm 1.44$ & 0.300 \\
(mean \pm SD) & & & \\
\hline
\end{tabular}

Group A delayed treatment; group B timely treatment; $S D$ standard deviation; $B C V A$ best corrected visual acuity (decimal)

Bold indicates significance $(P<0.05)$

pseudophakic overall, $P=0.850$ ), treatment ( $65 \%$ bevacizumab overall, $P=0.176)$, and treatment line (54.6\% first line, $P=0.575$ ).

Table 2 summarizes the ocular findings at the last examination before the COVID-19 lockdown.

The patients in both groups presented with statistically similar mean BCVAs at the commencement of intravitreal anti-VEGF injections: $0.47 \pm 0.26$ and $0.43 \pm 0.34$ decimal for groups $\mathrm{A}$ and $\mathrm{B}$, respectively $(P=0.5)$. However, group B sustained significantly more outcomes that were anatomically and functionally poorer as measured from the time of treatment commencement to the last pre-COVID-19 lockdown examination. Specifically, after a similar treatment period of $2.69 \pm 2.09$ and $2.33 \pm 1.44$ years in groups $\mathrm{A}$ and $\mathrm{B}$, respectively $(P=0.3)$, the group $\mathrm{B}$ eyes had poorer BCVAs than the group A eyes $(0.33$ vs. 0.48 decimal, respectively, $P=0.007)$. Their BCVA was less likely to have significantly improved under treatment $(\triangle \mathrm{BCVA}>0.1$ decimal of $40 \%$ for group A vs. $15 \%$ for group $\mathrm{B}, P=0.005$ ) and more likely to have deteriorated BCVA $(\triangle \mathrm{BCVA}<0.1$ of $12 \%$ for group A vs. $34 \%$ for group $\mathrm{B}, P=0.010)$. These findings were reflected by the OCT imaging findings, where the group B eyes had a central subfield $26 \%$ thicker than 
Table 2 Pre-COVID characteristics

\begin{tabular}{lllr}
\hline & Group A & Group B & $P$ value \\
\hline Pre-COVID BCVA (mean \pm SD) & $0.48 \pm 0.27$ & $0.33 \pm 0.28$ & $\mathbf{0 . 0 0 7}$ \\
Number of eyes BCVA $<0.1$ pre-COVID $(\%)$ & $5(10.4)$ & $7(9.9)$ & 1.000 \\
BCVA change since presentation until last pre-COVID check & & & \\
$\quad$ Improved $(\Delta$ BCVA $>0.1)(\%)$ & $19(40)$ & $11(15)$ & $\mathbf{0 . 0 0 5}$ \\
Worsened $(\Delta$ BCVA $<0.1)(\%)$ & $6(12)$ & $24(34)$ & $\mathbf{0 . 0 1 0}$ \\
$\quad$ Stable $(-0.1<\Delta$ BCVA $<0.1)(\%)$ & $23(48)$ & $36(51)$ & 0.850 \\
OCT anatomical findings & & & \\
Pre-COVID OCT macular thickness $(\mu)($ mean \pm SD) & $294 \pm 54$ & $372 \pm 103$ & $<\mathbf{0 . 0 0 1}$ \\
Presence of fluids (IRF or SRF) or blood at pre-COVID lockdown check & & \\
IRF, $n(\%)$ & $21(43.7)$ & $29(40.8)$ & 0.850 \\
SRF, $n(\%)$ & $15(31.2)$ & $18(25.3)$ & 0.530 \\
Blood, $n(\%)$ & $1(2.0)$ & $2(2.8)$ & 1.000 \\
Planned interval duration $($ weeks $)($ mean \pm SD) & $5.7 \pm 2.7$ & $5.4 \pm 2.4$ & 0.600 \\
\hline
\end{tabular}

Group A delayed treatment; group B timely treatment; $B C V A$ best corrected visual acuity (decimal); IRF intraretinal fluid; $S R F$ subretinal fluid; $S D$ standard deviation; $O C T$ ocular computerized tomography

OCT macular thickness relates to the central subfield total retinal thickness as defined by the standard ETDRS grid

Bold indicates statistical significance $(P<0.05)$ those of group A $(294 \pm 54 \mu \mathrm{m}$ for group A vs. $372 \pm 103 \mu \mathrm{m}$ for group B, $P<0.001)$ at the last pre-COVID-19 lockdown checkup.

\section{Outcome analysis}

Table 3 summarizes the changes in clinical and imaging findings over the last visit-before the first wave COVID-19 lockdown period to the first visit afterwards.

\section{Visual acuity}

The BCVA worsened significantly in 23 group A eyes (47.9\%) compared to 6 group B eyes (8.5\%) (odds ratio [OR] 9.97, $P<0.001)$ over the first wave COVID-19 lockdown period. The BCVA improved in 2 group A eyes (4.2\%) compared with 9 group B eyes (12.7\%) (OR 0.30, $P=0.19$ ). The BCVA remained stable in $23(47.9 \%)$ and $56(78.9 \%)$ group $\mathrm{A}$ and $\mathrm{B}$ eyes, respectively (OR $0.25 P<0.001)$. The distribution of changes in BCVA is illustrated in Fig. 1.

\section{Anatomical}

Thickening of the central macular subfield $\left(\Delta_{\text {Thickness }}>50 \mu \mathrm{m}\right)$ was observed in $9(18.8 \%)$ group A eyes and none in the group B eyes $(P<0.001)$. Retinal thickness increased by $10 \%$ in 13 group A eyes $(27.1 \%)$, while there was no comparable increase in the group B eyes $(P<0.001)$.

\section{Stability}

Stability $\left(\Delta_{\text {Thickness }}<10 \%\right)$ was measured in $30(62.5 \%)$ group A eyes compared to $64(90.1 \%)$ group B eyes $(P=0.002)$. Figure 2 illustrates the distribution of changes in central subfield thickness.

\section{New or increased amounts of subretinal fluid or worsening}

These changes were detected in $20(41.6 \%)$ group A eyes compared to 7 (9.9\%) group $\mathrm{B}$ eyes $(\mathrm{OR}=6.53, P=0.022)$. New or increased amounts of intraretinal fluid were detected in 19 (39.6\%) group A eyes compared to 7 (19.7\%) group $\mathrm{B}$ eyes $(\mathrm{OR}=2.67, P<0.001)$. In group $\mathrm{A}$, macular hemorrhage appeared de novo in 4 (8.3\%) eyes, and did not resolve in 1 eye in which it had already been present prior to treatment disruption. Of the 4 eyes that were diagnosed with new macular hemorrhage, the planned interval between injections had been $4.5 \pm 1$ weeks and the actual interval was $10.3 \pm 1$ weeks. No new occurrence of macular hemorrhage was detected in the group B eyes. Furthermore, none of the $2(2.8 \%)$ eyes of the group B patients who had a macular hemorrhage in their pre-COVID-19 examination had evidence of a macular hemorrhage in their post-COVID-19 exam. When considering any form of anatomic features of worsening (defined as new subretinal or intraretinal fluids, increase of preexisting fluids, or new hemorrhage), the group A eyes fared worse: 31 (64.6\%) eyes compared to 16 (22.5\%) group $\mathrm{B}$ eyes $(\mathrm{OR}=5.73, P<0.001)$. Additional anatomic data are provided in Table 3. 
Table 3 Functional and anatomical changes in groups $\mathrm{A}$ and $\mathrm{B}$ pre- and post-COVID examination

\begin{tabular}{lllr}
\hline & Group A & Group B & $P$ value \\
\hline Changes in BCVA (decimal) from pre- to post-COVID-19 lockdown & & \\
$\quad$ Improved $(\Delta$ BCVA $>0.1)(\%)$ & $2(4.2)$ & $9(12.7)$ & 0.116 \\
Worsened $(\Delta$ BCVA $<0.1)(\%)$ & $23(47.9)$ & $6(8.5)$ & $<\mathbf{0 . 0 0 1}$ \\
$\quad$ Stable $(\%)$ & $23(47.9)$ & $56(78.9)$ & $<\mathbf{0 . 0 0 1}$ \\
Markers of CNV activity & & & \\
New or worse SRF, $n(\%)$ & $20(41.7)$ & $7(9.9)$ & $\mathbf{0 . 0 2 2}$ \\
New or worse IRF, $n(\%)$ & $19(39.6)$ & $14(19.7)$ & $<\mathbf{0 . 0 0 1}$ \\
Blood, $n(\%)$ & New, $4(8.3)$ & Disappearance, $2(2.8)$ & $\mathbf{0 . 0 2 4}$ \\
New or worse SRF, IRF, or new blood, $n(\%)$ & $30(62.5)$ & $16(22.5)$ & $<\mathbf{0 . 0 0 1}$ \\
Central macular thickness $(\mu)$ & & & $<\mathbf{0 . 0 0 1}$ \\
Pre-lockdown $($ mean \pm SD) & $293.7 \pm 54.4$ & $371.5 \pm 103.4$ & 0.223 \\
Post-lockdown $($ mean \pm SD) & $326 \pm 115.4$ & $348.8 \pm 73.7$ & $\mathbf{0 . 0 0 1}$ \\
Absolute macular thickness change, $\Delta \mu(\%)$ & $32.3(10.7)$ & $-22.7(-3.9)$ & $<\mathbf{0 . 0 0 1}$ \\
Reduction $(\Delta<50 \mu)(\%)$ & $9(18.8)$ & $0(0.0)$ & 0.239 \\
Increase $(\Delta>50 \mu)(\%)$ & $1(2.1)$ & $6(8.5)$ & 0.061 \\
Stability $(-50 \mu<\Delta<50 \mu)(\%)$ & $38(79.2)$ & $65(91.5)$ & $\mathbf{0 . 0 0 1}$ \\
Relative thickness change & & & 1.000 \\
Reduction $(\Delta<10 \%)(\%)$ & $13(27.1)$ & $0(0.0)$ & $\mathbf{0 . 0 0 2}$ \\
Increase $(\Delta>10 \%)(\%)$ & $5(10.4)$ & $7(9.9)$ & $64(90.1)$ \\
Stability $(-10 \%<\Delta<10 \%)(\%)$ & $30(62.5)$ & & \\
\hline
\end{tabular}

Group A delayed treatment; group B timely treatment; BCVA best corrected visual acuity (decimal); IRF intraretinal fluid; $S R F$ subretinal fluid; $C N V$ choroidal neovascular membrane; $O C T$ ocular computerized tomography

OCT macular thickness relates to the central subfield total retinal thickness as defined by the standard ETDRS grid. Pre- and post- refer to the first wave of COVID-19 lockdown

Bold indicates statistical significance $(P<0.05)$

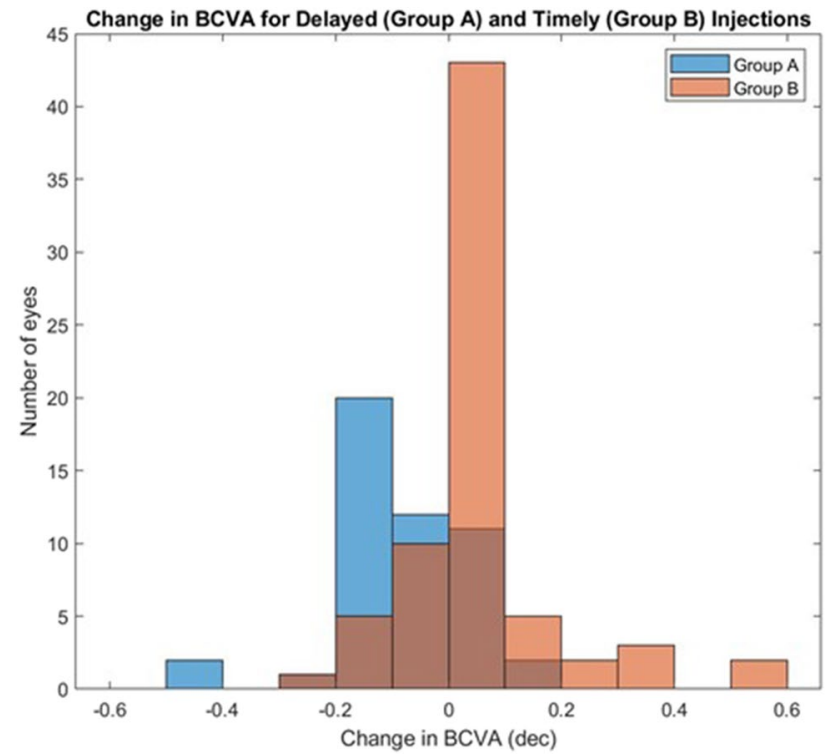

Fig. 1 Distribution of change in BCVA for delayed (group A, denoted in blue) and timely (group $\mathrm{B}$, denoted in orange) injection schedule. Overlapping bins (group A + group B) are denoted in brown

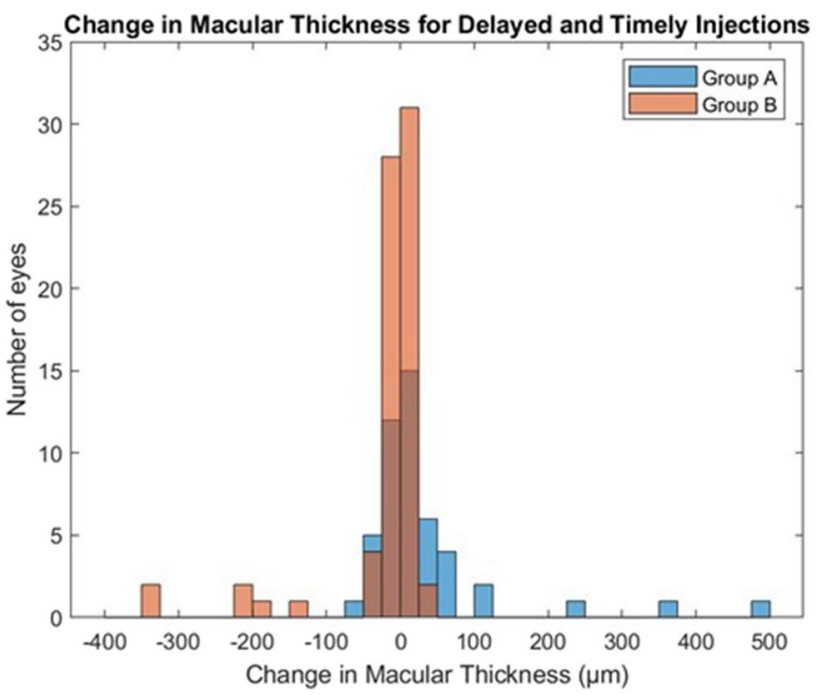

Fig. 2 Distribution of changes in central retinal thickness $(\mu \mathrm{m})$ for delayed (group A, denoted in blue) and timely (group B, denoted in orange) injection schedule. Overlapping bins (group A + group B) are denoted in brown 


\section{Correlation between anatomic and functional outcomes}

Increased retinal thickness correlated with worse function. The negative correlation between retinal thickness and BCVA was seen in the pre-COVID-19 exam (Pearson correlation coefficient $-0.266, P=0.004)$ as well as in the postCOVID-19 exam (Pearson correlation coefficient -0.240 , $P=0.009)$ of all study patients in combination. A linear regression model of BCVA against retinal thickness yielded a significant correlation that was, however, clinically minute (i.e., a decrease of 0.075 decimal in VA for an increase in thickness of $100 \mu$ ). The BCVA remained stable in 2 eyes of the patients in group A that had sustained a new macular hemorrhage ( 1 eye with low vision of 0.01 decimal, the second eye 0.7 decimal), and decreased in 2 other eyes (from 0.02 to 0.005 decimal and from 0.25 to 0.2 decimal).

\section{Correlation between delay in injection and adverse outcome}

There was no correlation between delay in injection and either change in OCT central thickness or change in VA in the group A eyes $\left(R^{2}=0.01\right)$ (Supplementary Figs. 1 and 2).

\section{Discussion}

In this study, we estimated the impact of delayed intravitreal injection on the short-term visual and anatomic outcomes for nvAMD patients based on data from a single retina unit in a tertiary referral center in Israel. As expected, our results showed that a delay in the delivery of anti-VEGF injections was associated with adverse outcomes. Almost one-half of the patients who missed their scheduled appointments sustained a decrease in BCVA, while OCT revealed features of worsening in $64 \%$ of them. Morphologic worsening correlated with decrease in VA but only weakly, which is consistent with more controlled studies published prior to the pandemics [23].

In order to get second-line treatment in the Israeli Health system, a patient has to make a specific effort, including dealing with many administrative issues. This could explain that such patients, having often struggled to get reimbursement, are more prone to show up for injections than those treated with the easily obtainable bevacizumab as first-line or fourth-line agent or those receiving third-line therapy already acquainted with the administrative process. When dealing with compliance, psychological issues should not be underestimated.

The importance of regular delivery of anti-VEGF to preserve structure and function in nvAMD was demonstrated in earlier well-controlled studies [4, 24]. Data from recent real-life observations confirmed that delaying injections was associated with functional impairment [5, 6]. As a major disrupter of retinal care, the COVID-19 pandemic resulted in a massive breach of the therapeutic protocols. While several reports analyzed the impact of this worldwide event on nvAMD patients [8, 25-31], only a few of them had looked at the effects on both structural and functional outcomes. To the best of our knowledge, our current report is the first to specifically compare patients who missed injections during the first wave of COVID-19 with patients who followed their original therapeutic plan during the same period.

Our data show that both subretinal and intraretinal fluid either appeared de novo or worsened in the nvAMD eyes of patients who deviated from their injection schedule. More worryingly, macular hemorrhage, which is a complication often associated with irreversible damage [32], appeared in $8.3 \%$ of our patients when the intravitreal injection was delayed, an issue already raised by Romano et al. [33].

Interestingly, no correlation was found between delay in treatment and either change in OCT central thickness or change in BCVA. We speculate that the absence of any such correlation might indicate that people who had noticed a worsening of their VA adhered to their treatment schedule despite any trepidation they may have had in association with the COVID-19 outbreak.

Our study has several limitations starting with its retrospective design which could be associated with selection bias. We tried to contain this issue by defining a control group (group B) and analyzing our data as both discrete and continuous values. In addition, 19 patients scheduled for periodic injections were absent throughout the entire study period and we are unable to determine their functional and anatomic outcomes. Our small sample size, confined to one region in Israel, also limits the power of the analysis. This assessment should, therefore, be considered a pilot study: a long-term follow-up analysis on a larger cohort is needed to determine the degree and irreversibility of macular damage in nvAMD patients who did not undergo uninterrupted antiVEGF therapy.

The findings of our study demonstrate the real-world deleterious effect of the COVID-19 pandemic on compliance with intravitreal therapy among nvAMD patients and, specifically, its morphological and functional impact. Patients should preemptively be actively sought in an effort to prevent irreversible loss of vision.

Supplementary Information The online version contains supplementary material available at https://doi.org/10.1007/s00417-021-05505-5.

Author contribution All authors contributed to the study conception and design. Material preparation, data collection, and analysis were performed by Joel Hanhart, Rony Wiener, and Hashem Totah. The first draft of the manuscript was written by Joel Hanhart and all authors commented on previous versions of the manuscript. All authors read and approved the final manuscript. 
Data availability All anonymized materials are available on request.

Code availability Not applicable.

\section{Declarations}

Ethics approval Institutional Ethics Committee, research project "impact of COVID-19 related non-compliance with anti-VEGF treatment on neovascular AMD course," approval 0253-20-SZMC.

Consent to participate Not applicable.

Consent for publication Not applicable.

Conflict of interest The authors declare no competing interests.

\section{References}

1. Rosenfeld PJ, Brown DM, Heier JS, Boyer DS, Kaiser PK, Chung CY, Kim RY (2006) Ranibizumab for neovascular age-related macular degeneration. N Engl J Med 355:1419-1431. https://doi. org/10.1056/NEJMoa054481

2. Brown DM, Michels M, Kaiser PK, Heier JS, Sy JP, Ianchulev T (2009) Ranibizumab versus verteporfin photodynamic therapy for neovascular age-related macular degeneration: two-year results of the ANCHOR study. Ophthalmology 116:57-65.e55. https://doi. org/10.1016/j.ophtha.2008.10.018

3. Grzybowski A, Told R, Sacu S, Bandello F, Moisseiev E, Loewenstein A, Schmidt-Erfurth U (2018) 2018 Update on Intravitreal Injections: Euretina Expert Consensus Recommendations. Ophthalmologica 239:181-193. https://doi.org/10.1159/000486145

4. Solomon SD, Lindsley K, Vedula SS, Krzystolik MG, Hawkins BS (2019) Anti-vascular endothelial growth factor for neovascular age-related macular degeneration. Cochrane Database Syst Rev 3:Cd005139. https://doi.org/10.1002/14651858.CD005139.pub4

5. Mehta H, Kim LN, Mathis T, Zalmay P, Ghanchi F, Amoaku WM, Kodjikian L (2020) Trends in real-world neovascular AMD treatment outcomes in the UK. Clin Ophthalmol 14:3331-3342. https://doi.org/10.2147/opth.S275977

6. Mehta H, Tufail A, Daien V, Lee AY, Nguyen V, Ozturk M, Barthelmes D, Gillies MC (2018) Real-world outcomes in patients with neovascular age-related macular degeneration treated with intravitreal vascular endothelial growth factor inhibitors. Prog Retin Eye Res 65:127-146. https://doi.org/10.1016/j.preteyeres. 2017.12.002

7. Babu N, Kohli P, Mishra C, Sen S, Arthur D, Chhablani D, Baliga G, Ramasamy K (2020) To evaluate the effect of COVID-19 pandemic and national lockdown on patient care at a tertiary-care ophthalmology institute. Indian J Ophthalmol 68:1540-1544. https://doi.org/10.4103/ijo.IJO_1673_20

8. Borrelli E, Grosso D, Vella G, Sacconi R, Battista M, Querques L, Zucchiatti I, Prascina F, Bandello F, Querques G (2020) Shortterm outcomes of patients with neovascular exudative AMD: the effect of COVID-19 pandemic. Graefes Arch Clin Exp Ophthalmol 258:2621-2628. https://doi.org/10.1007/s00417-020-04955-7

9. Carnevali A, Giannaccare G, Gatti V, Scuteri G, Randazzo G, Scorcia V (2021) Intravitreal injections during COVID-19 outbreak: real-world experience from an Italian tertiary referral center. Eur J Ophthalmol 31:10-12. https://doi.org/10.1177/11206 72120962032

10. Chaudhary V, Rosenberg D, Barbosa J, Qian C, Berger A, Whelan J, Kherani A, Samad A, Noble J (2020) National survey of Canadian Retina Society members on guidelines for ophthalmic care during the COVID-19 crisis: Canadian Retina Research Network (CR2N) COVID-19 Steering Committee analysis. Can J Ophthalmol 55:452-454. https://doi.org/10.1016/j.jcjo.2020.06. 001

11. El Hamichi S, Gold A, Heier J, Kiss S, Murray TG (2020) Impact of the COVID-19 pandemic on essential vitreoretinal care with three epicenters in the United States. Clin Ophthalmol 14:25932598. https://doi.org/10.2147/opth.S267950

12. Gegúndez-Fernández JA, Llovet-Osuna F, Fernández-Vigo JI, Mendicute Del Barrio J, Pablo-Júlvez L, Muñoz-Negrete FJ, Zarranz-Ventura J, Durán de la Colina J, de Rojas SV, JiménezAlfaro I, Calonge-Cano M, Galindo-Ferreiro A, Castillo-Gómez A, Mantolán-Sarmiento C, Duch-Samper A, Álvarez de ToledoElizalde J, Duch-Mestres F, Elies-Amat D, Ortega-Usobiaga J, Saornil-Alvarez MA, Villarrubia Cuadrado A, Garay Aramburu G, Fonollosa Carduch A, Cordero Coma JM, García Delpech S, Cárceles Cárceles JA, Del Castillo B, Sánchez JM, de Liaño G, Sánchez P, Harto Castaño M, Arias Puente A, García-Layana A (2021) Recommendations for ophthalmologic practice during the easing of COVID-19 control measures. Acta Ophthalmol. https:// doi.org/10.1111/aos.14752

13. Hattenbach LO, Heinz P, Feltgen N, Hoerauf H, Kohnen T, Priglinger S, Bachmann W, Rieks J, Eter N, Reinhard T (2020) Impacts of the SARS-CoV-2 pandemic on ophthalmic care in Germany. Ophthalmologe 117:892-904. https://doi.org/10.1007/ s00347-020-01220-4

14. Hoeferlin C, Hosseini H (2021) Review of clinical and operative recommendations for ophthalmology practices during the COVID-19 pandemic. SN Compr Clin Med: 1-6. https://doi.org/ 10.1007/s42399-020-00633-1

15. Koh AHC, Koh LRS, Sheu SJ, Sakamoto T (2020) What COVID19 has taught us: lessons from around the globe. Graefes Arch Clin Exp Ophthalmol 258:2091-2094. https://doi.org/10.1007/ s00417-020-04791-9

16. Korobelnik JF, Loewenstein A, Eldem B, Joussen AM, Koh A, Lambrou GN, Lanzetta P, Li X, Lövestam-Adrian M, Navarro R, Okada AA, Pearce I, Rodríguez FJ, Wong DT, Wu L (2020) Guidance for anti-VEGF intravitreal injections during the COVID-19 pandemic. Graefes Arch Clin Exp Ophthalmol 258:1149-1156. https://doi.org/10.1007/s00417-020-04703-x

17. Madanagopalan VG, Sriram Gopal MR, Sengupta S (2020) Perspectives of physicians in general and ophthalmologists in particular about restarting services post-COVID-19 lockdown. Indian J Ophthalmol 68:1401-1406. https://doi.org/10.4103/ijo.IJO_1221_ 20

18. Moussa M, Elshorbagy MS, Emarah A, Gaber R, Moussa OM, ElBradey M, Alagorie AR, Sorour OA (2021) Intravitreal injections of anti-VEGF agents during COVID-19 pandemic: clinical audit from Tanta University Hospital. Int Ophthalmol: 1-7. https://doi. org/10.1007/s10792-021-01719-y

19. Sacconi R, Borrelli E, Vella G, Querques L, Prascina F, Zucchiatti I, Bandello F, Querques G (2020) TriPla Regimen: a new treatment approach for patients with neovascular age-related macular degeneration in the COVID-19 "era". Eur J Ophthalmol: 1120672120963448. https://doi.org/10.1177/1120672120963448

20. Toro MD, Brézin AP, Burdon M, Cummings AB, Evren Kemer O, Malyugin BE, Prieto I, Teus MA, Tognetto D, Törnblom R, Posarelli C, Choragiewicz T, Rejdak R (2021) Early impact of COVID-19 outbreak on eye care: insights from EUROCOVCAT group. Eur J Ophthalmol 31:5-9. https://doi.org/10.1177/11206 72120960339

21. Xu D, Starr MR, Boucher N, Chiang A, Yonekawa Y, Klufas MA, Khan MA, Cohen MN, Mehta S, Kuriyan AE (2020) Real-world vitreoretinal practice patterns during the 2020 COVID-19 pandemic: a nationwide, aggregated health record analysis. Curr Opin 
Ophthalmol 31:427-434. https://doi.org/10.1097/icu.0000000000 000692

22. Wasser LM, Weill Y, Brosh K, Magal I, Potter M, Strassman I, Gelman E, Koslowsky M, Zadok D, Hanhart J (2020) The impact of COVID-19 on intravitreal injection compliance. SN Compr Clin Med: 1-4. https://doi.org/10.1007/s42399-020-00614-4

23. Staurenghi G, Garweg JG, Gerendas BS, Macfadden W, Gekkiev B, Margaron P, Dunger-Baldauf C, Kolar P (2020) Functional versus functional and anatomical criteria-guided ranibizumab treatment in patients with neovascular age-related macular degeneration - results from the randomized, phase IIIb OCTAVE study. BMC Ophthalmol 20:18. https://doi.org/10.1186/ s12886-019-1251-6

24. Patel RD, Momi RS, Hariprasad SM (2011) Review of ranibizumab trials for neovascular age-related macular degeneration. Semin Ophthalmol 26:372-379. https://doi.org/10.3109/08820 538.2011.570845

25. Borrelli E, Grosso D, Vella G, Sacconi R, Querques L, Zucchiatti I, Prascina F, Bandello F, Querques G (2020) Impact of COVID19 on outpatient visits and intravitreal treatments in a referral retina unit: let's be ready for a plausible "rebound effect." Graefes Arch Clin Exp Ophthalmol 258:2655-2660. https://doi.org/10. 1007/s00417-020-04858-7

26. Sindal MD, Chhabra K, Khanna V (2021) Profile of patients receiving intravitreal anti-vascular endothelial growth factor injections during COVID-19-related lockdown. Indian J Ophthalmol 69:730-733. https://doi.org/10.4103/ijo.IJO_2807_20

27. Yang KB, Feng H, Zhang H (2020) Effects of the COVID-19 pandemic on anti-vascular endothelial growth factor treatment in China. Front Med (Lausanne) 7:576275. https://doi.org/10.3389/ fmed.2020.576275
28. Ashkenazy N, Goduni L, Smiddy WE (2021) Short-term effects of COVID-19-related deferral of intravitreal injection visits. Clin Ophthalmol 15:413-417. https://doi.org/10.2147/opth.S296345

29. Naravane AV, Mundae R, Zhou Y, Santilli C, van Kuijk F, Nazari H, Yamanuha J, Emerson GG, Koozekanani DD, Montezuma SR (2021) Short term visual and structural outcomes of anti-vascular endothelial growth factor (anti-VEGF) treatment delay during the first COVID-19 wave: a pilot study. PLoS One 16:e0247161. https://doi.org/10.1371/journal.pone.0247161

30. Song W, Singh RP, Rachitskaya AV (2021) The effect of delay in care among patients requiring intravitreal injections. Ophthalmol Retina. https://doi.org/10.1016/j.oret.2020.12.020

31. Yang K-B, Feng H, Zhang H (2020) Effects of the COVID-19 pandemic on anti-vascular endothelial growth factor treatment in China. Front Med 7. https://doi.org/10.3389/fmed.2020.576275

32. Stanescu-Segall D, Balta F, Jackson TL (2016) Submacular hemorrhage in neovascular age-related macular degeneration: a synthesis of the literature. Surv Ophthalmol 61:18-32. https://doi. org/10.1016/j.survophthal.2015.04.004

33. Romano F, Monteduro D, Airaldi M, Zicarelli F, Parrulli S, Cozzi M, Staurenghi G (2020) Increased number of submacular hemorrhages as a consequence of coronavirus disease 2019 lockdown. Ophthalmol Retina 4:1209-1210. https://doi.org/10.1016/j.oret. 2020.06.027

Publisher's note Springer Nature remains neutral with regard to jurisdictional claims in published maps and institutional affiliations. 